\title{
Extended Cost Benefit Analysis of Bauxite Mining and Processing in the Central Highlands of Vietnam
}

\author{
Trinh Phuong Ngoc ${ }^{1, *}$, Hoang Xuan $\mathrm{Co}^{2}$ \\ ${ }^{1}$ Tan Trao University, km6 Trung Mon, Yen Son, Tuyen Quang, Viet Nam \\ ${ }^{2}$ VNU University of Science, Vietnam National University, Hanoi, 334 Nguyen Trai, Hanoi, Vietnam \\ Received 03 February 2020 \\ Revised 12 April 2020; Accepted 15 April 2020
}

\begin{abstract}
The study focuses on assessing the effectiveness of bauxite mining and processing in the Central Highlands through the example of Tan Rai (Lam Dong) and Nhan Co (Dak Nong) bauxitealumina complexes by the method of extended cost benefit analysis. External costs have been localized to be taken into account, including opportunity costs, environmental costs, corporate social responsibility costs and contingency costs for environmental incidents. The results showed that if calculating the environmental costs, the Tan Rai complex does not bring effectiveness for society with a negative NPV value (VND -5,167,422 million), IRR (6.27\%) is lower than the discount (10\%); Nhan Co complex is effective with positive NPV (VND 145,862 million), IRR (10.1\%) is higher than the discount $(10 \%)$, but the operation of this complex is risky when analyzing the sensitivity of the indicators. A ton of alumina will require an average from VND 0.7 to 0.9 million of environmental costs. In a year, two bauxite-alumina complexes in the Central Highlands create stable jobs for thousands of workers, contributing from VND 1,200 to 1,400 billion of taxes and fees for the State, equivalent to between VND 1.0 and 1.2 million per ton of alumina. From the lessons learned from Tan Rai and Nhan Co complexes, the future bauxite mining and processing projects need to be implemented on schedule and operate at $100 \%$ of the designed capacity right from the first year to achieve optimal efficiency. In the future, it is necessary to develop and evaluate the effectiveness of closed, full and chain options to improve the operational efficiency of bauxite projects, aiming to thoroughly solve the environmental issues by improving technological processes, implementing land restoration after mining, applying cleaner production solutions.
\end{abstract}

Keywords: Bauxite, Alumina, Central Highlands, Extended Cost Benefit Analysis, Effectiveness.

\footnotetext{
* Corresponding author.

E-mail address: gemytrinh@gmail.com
}

https://doi.org/10.25073/2588-1094/vnuees.4534 


\title{
Phân tích chi phí - lợi ích mở rộng hoạt động khai thác, chế biến khoáng sản bauxite Tây Nguyên
}

\author{
Trịnh Phương Ngọc ${ }^{1, *}$, Hoàng Xuân $\mathrm{Co}^{2}$ \\ ${ }^{1}$ Truoòng Đại học Tân Trào, km6, Trung Môn, Yên Sơn, Tuyên Quang, Việt Nam \\ ${ }^{2}$ Truờng Đại học Khoa học Tự nhiên, Đại học Quốc gia Hà Nội, 334 Nguyễn Trãi, Hà Nội, Việt Nam
}

Nhận ngày 03 tháng 02 năm 2020

Chỉnh sửa ngày 12 tháng 04 năm 2020; Chấp nhận đăng ngày 15 tháng 4 năm 2020

\begin{abstract}
Tóm tắt: Nghiên cứu tập trung đánh giá hiệu quả của hoạt động khai thác, chế biến khoáng sản bauxite Tây Nguyên qua nghiên cứu mẫu tại tổ hợp bauxite-alumina Tân Rai (Lâm Đồng) và Nhân Cơ (Đắk Nông) bằng phương pháp phân tích chi phí - lợi ích mở rộng. Các chi phí ngoại ứng đã được nội hoá để đưa vào tính toán, bao gồm chi phí cơ hội, chi phí môi trường, chi phí trách nhiệm xã hội của doanh nghiệp và chi phí dự phòng cho sự cố môi trường. Kết quả phân tích chi phí - lợi ích mở rộng cho thấy, nếu tính toán đầy đủ các khoản chi phí môi trường thì tổ hợp Tân Rai không đem lại hiệu quả cho xã hội với giá trị NPV âm (-5.167.422 triệu đồng), IRR (6,27\%) thấp hơn tỷ lệ chiết khấu (10\%); Tổ hợp Nhân Cơ hoạt động hiệu quả với NPV dương (145.862 triệu đồng), IRR $(10,1 \%)$ cao hơn tỷ lệ chiết khấu $(10 \%)$, tuy nhiên hoạt động của tổ hợp này chứa nhiều rủi ro khi phân tích độ nhạy của các chỉ số tính toán. Trung bình 1 tấn sản phẩm alumina sản xuất ra cần từ 0,7 đến 0,9 triệu đồng chi phí môi trường. Hai tổ hợp bauxite-alumina ở Tây Nguyên một năm tạo việc làm ổn định cho hàng nghìn lao động, đóng góp khoảng 1.200-1.400 tỷ đồng các khoản thuế, phí cho Nhà nước, tương đương từ 1,0 đến 1,2 triệu đồng/ 1 tấn sản phẩm. Từ bài học kinh nghiệm của tổ hợp Tân Rai và Nhân Cớ, các dự án khai thác, chế biến bauxite sau này cần được triển khai đúng tiến độ và vận hành $100 \%$ công suất thiết kế ngay từ năm đầu tiên để đạt mức hiệu quả tối ưu. Trong tương lai, cần xây dựng và đánh giá hiệu quả các phương án khai thác, chế biển theo chuỗi khép kín, tận thu, chế biến sâu để cải thiện hiệu quả hoạt động của các dự án bauxite, hướng tới giải quyết triệt để các vấn đề môi trường bằng cải tiến quy trình công nghệ, thực hiện hoàn thổ phục hồi môi trường, áp dụng các giải pháp sản xuất sạch hơn.
\end{abstract}

Từ khoá: bauxite, alumina, Tây Nguyên, phân tích chi phí - lợi ích mở rộng, hiệu quả.

\section{Mở đầu}

Bauxite là quặng dùng để sản xuất alumina, rồi từ đó điện phân ra nhôm kim loại. Tuỳ thuộc vào loại quặng, cần khoảng 4-6 tấn bauxite để sản xuất 2 tấn alumina và điện phân được 1 tấn nhôm kim loại [1]. Theo Cục khảo sát địa chất Hoa Kỳ năm 2019, nguồn tài nguyên toàn cầu của bauxite ước tính khoảng 55 đển 75 tỷ tấn, tập trung chủ yếu ở Châu Phi (32\%), Châu Đại Dương (23\%), Nam Mỹ và Caribê (21\%), Châu
Á (18\%) và các nơi khác $(6 \%)$, đủ để đáp ứng nhu cầu của thế giới về kim loại nhôm trong tương lai. Trên thể giới, quặng bauxite chủ yếu phân bố ở Úc, Brazil, Jamaisa, Nga, Hungary, Guyana, Ân Độ, Trung Quốc, Indonesia, Việt Nam. Trong đó, Việt Nam là nước có trữ lượng bauxite đứng thứ 3 trên thế giới (3,7 tỷ tấn), chỉ sau Guinea và Úc [2]. Hiện nay, sản lượng khai thác và chế biến quặng bauxite ở Việt Nam còn rất thấp so với quy mô về trữ lượng.

\footnotetext{
* Tác giả liên hệ.

Địa chi email: gemytrinh@gmail.com

https://doi.org/10.25073/2588-1094/vnuees.4534
} 
Ở nước ta, quặng bauxite tập trung chủ yếu ở khu vực Tây Nguyên. Tổ hợp bauxite - alumina Tân Rai ở Lâm Đồng và Nhân Cơ ở Đắk Nông là hai dự án thí điểm đầu tiên ở Tây Nguyên theo chỉ đạo của Bộ Chính Trị do Tập đoàn Than Khoáng sản Việt Nam (TKV) làm Chủ đầu tư. Tổ hợp Tân Rai được khởi công năm 2008, sản xuất alumina từ năm 2013 và sau 10 năm triển khai, nhà máy đã hoạt động $100 \%$ công suất thiết kế vào năm 2018. Tổ hợp Nhân Cơ được khởi công năm 2010, sản xuất alumina từ năm 2017 và hoạt động $100 \%$ công suất từ năm 2018 . Do vậy, việc đánh giá hiệu quả kinh tế môi trường của các dự án thí điểm ở giai đoạn này nhằm phục vụ công tác quản lý và quy hoạch ngành công nghiệp nhôm được cho là hợp lý, kịp thời và có ý nghĩa cả trên phương diện pháp lý, khía cạnh khoa học và trên cơ sở dữ liệu thực tế.

Nhà máy alumina Tân Rai và Nhân Cơ có công suất thiết kế 650.000 tấn alumina/năm, thời gian hoạt động là 30 năm. Khu vực Tổ hợp bauxite - alumina Tân Rai và Nhân Cơ có diện tích lần lượt là 2.200 ha và 4.100 ha, số lao động khu vực tổ hợp Tân Rai khoảng 1.400 người, ở tổ hợp Nhân Cơ là 1.100 người, đa phần hoạt động của các tổ hợp đều được cơ giới hóa $[3,4]$. Quặng bauxite được khai thác bằng công nghệ lộ thiên, sau đó qua quá trình tuyển rửa để thu hồi quặng tinh. Quặng tinh được vận chuyển đến nhà máy alumina bằng băng tải. Alumina được sản xuất bằng công nghệ Bayer, có dạng bột màu trắng mịn, hàm lượng $\mathrm{Al}_{2} \mathrm{O}_{3}$ đạt $98,5 \%$ và là nguyên liệu dùng để điện phân nhôm. Các chất không hòa tan chứa nhiều xút và oxalat gọi là "bùn đỏ" được thải bỏ ra các hồ chứa gần khu vực nhà máy. Alumina được đóng gói và vận chuyển bằng ô tô với cự ly $210 \mathrm{~km}$ từ nhà máy Tân Rai và $250 \mathrm{~km}$ từ nhà máy Nhân Cơ đến cảng Gò Dầu, Đồng Nai để xuất khẩu.

Hoạt động khai thác, chế biến bauxite mang lại nguồn lợi đáng kể từ việc tạo ra nguyên liệu để sản xuất nhôm, xuất khẩu sản phẩm, phát triển cơ sở hạ tầng và tạo công ăn việc làm cho người dân địa phương. Tuy nhiên, những vấn đề nảy sinh trong quá trình triển khai thực tế như chậm tiến độ thực hiện, tăng tổng mức đầu tư, giá thành sản xuất cao, những tồn tại trong di dân và đền bù sinh kế, rủi ro hồ bùn đỏ và phục hồi môi trường sau khai thác đã làm cho hiệu quả của các tổ hợp bauxite - alumina Tây Nguyên không được như kỳ vọng và trở thành một thách thức lớn đối với các cơ quan quản lý nhà nước nói chung và các nhà quản lý môi trường nói riêng.

Kết quả tính toán hiệu quả các dự án bauxitealumina của TKV năm 2013 cho thấy, tổ hợp Tân Rai sẽ đem lại hiệu quả kinh tế với NPV bằng 2.171.009 triệu đồng, hệ số hoàn vốn nội bộ IRR là $8,21 \%$, thời gian thu hồi vốn là 11,85 năm; tổ hợp Nhân Cơ cho giá trị NPV bằng 1.406.267 triệu đồng, hệ số hoàn vốn nội bộ IRR là $7,62 \%$, thời gian hoàn vốn 12,99 năm (Bảng 1 ). Theo kết quả này, các chỉ tiêu về hiệu quả kinh tế của tổ hợp Tân Rai đều cao hơn so với tổ hợp Nhân Cơ.

Bảng 1. Kết quả tính toán hiệu quả kinh tế tổ hợp bauxite - alumina Tân Rai và Nhân Cơ của TKV năm 2013 [3]

\begin{tabular}{|c|l|c|c|c|}
\hline TT & \multicolumn{1}{|c|}{ Chỉ tiêu kinh tế } & Tổ hợp Tân Rai & Tổ hợp Nhân Cơ & Đơn vị \\
\hline 1 & Vốn đầu tư ban đầu & 15.117 .799 & 16.018 .058 & Triệu đồng \\
\hline 2 & Giá thành sản xuất toàn bộ bình quân & 6.549 .109 & 6.655 .591 & Đồng/tấn \\
\hline 3 & Giá bán alumina bình quân & 7.957 .414 & 7.959 .417 & Đồng/tấn \\
\hline 4 & Lợi nhuận trước thuế bình quân & 1.155 .968 & 1.032 .901 & Triệu đồng/năm \\
\hline 5 & Lợi nhuận sau thuế bình quân & 896.956 & 832.999 & Triệu đồng/năm \\
\hline 6 & Các khoản thuế phải nộp bình quân & 422.089 & 272.524 & Triệu đồng/năm \\
\hline 7 & Phí bảo vệ môi trường & 125.531 & 125.531 & Triệu đồng/năm \\
\hline 8 & r & 6,86 & 6,81 & $\%$ \\
\hline 9 & NPV & 2.171 .009 & 1.406 .267 & Triệu đồng \\
\hline 10 & IRR (\%) & 8,21 & 7,62 & \% \\
\hline 11 & Thời gian thu hồi vốn & 11,85 & 12,99 & Năm \\
\hline
\end{tabular}


Doanh nghiệp lựa chọn tỷ lệ chiết khấu bằng $6,81-6,86 \%$. Con số này chưa thể hiện được đầy đủ ý nghĩa của tỷ lệ chiết khấu gồm có tỷ lệ sinh lợi thực tế, tỉ lệ lạm phát và rủi ro. Tỷ lệ chiết khấu này cũng thấp hơn nhiều lần so với lãi suất mà doanh nghiệp phải chịu khi vay vốn trong nước là $10 \%$ [3].

Đã 7 năm trôi qua kể từ khi TKV công bố kết quả tính toán về hiệu quả kinh tế của tổ hợp Tân Rai, đến nay đã có nhiều thay đổi trong Luật và Chính sách của nhà nước về các nội dung thuế và phí liên quan đến tài nguyên bauxite. Các thay đổi này cụ thể như sau:

- Thời điểm tính toán của $\mathrm{TKV}$, alumina là mặt hàng được hưởng chính sách ưu đãi với thuế suất xuất khẩu $0 \%$. Từ năm 2016 đến nay, theo quy định của Chính phủ, thuế suất đang áp dụng đối với mặt hàng này là $2 \%[5]$.

- TKV áp dụng thuế tài nguyên là 140.000đ/tấn quặng nguyên khai theo Quyết định về giá tính thuế tài nguyên quặng bauxite năm 2013 của UBND tỉnh Lâm Đồng và Đắk Nông. Từ năm 2017, thực hiện theo Thông tư của Bộ Tài chính [6], tỉnh Lâm Đồng và Đắk Nông áp dụng giá tính thuế tài nguyên quặng bauxite là 390.000đ/tấn quặng.

- Ở thời điểm tính toán, TKV chưa tính tiền cấp quyền khai thác khoáng sản, tiền thuê đất hàng năm.

Trong thực tế, các tính toán về hiệu quả dự án thường là công bố của doanh nghiệp. Vì mục đích của doanh nghiệp là tối đa hoá lợi nhuận nền các chi phí liên quan đến xã hội và môi trường như chi phí cơ hội, chi phí môi trường, phục hồi môi trường sau khai thác, trách nhiệm xã hội của doanh nghiệp,... đã không được đưa vào tính toán hiệu quả của các dự án bauxite.

Trong khi đó, thực tế hoạt động khai thác khoáng sản đem lại rất nhiều lợi ích cho doanh nghiệp, nhưng những thiệt hại về môi trường và xã hội thường chưa được tính toán cụ thể và đầy đủ. Thực trạng này cho thấy sự cần thiết của việc đánh giá hiệu quả kinh tế môi trường trong quản lý tài nguyên khoáng sản bauxite.

\section{Phương pháp và số liệu}

\subsection{Phương pháp phân tích chi phí-lơi ich}

Phương pháp phân tích chi phí - lợi ích là phương pháp đã và đang được áp dụng phổ biến trong đánh giá hiệu quả kinh tế của các dự án phát triển. Trong giai đoạn lập dự án, kết quả phân tích chi phí - lợi ích cho biết khả năng đem lại hiệu quả kinh tế của dự án giúp cơ quan quản lý có cơ sở cho phép thực hiện đầu tư [7].

Khi dự án đi vào hoạt động, phương pháp này được sử dụng để đánh giá khả năng thực hiện so với thuyết minh, dự báo đã xây dựng. Với số liệu chi phí, lợi ích thực tế trong những năm đã thực hiện và xu thế trong những năm tiếp theo sẽ tính được các chỉ tiêu kinh tế, so sánh với phân tích trước khi thực hiện dự án sẽ biết rõ những vấn đề nảy sinh để có biện pháp giải quyết kịp thời. Trong kinh tế môi trường, phương pháp phân tích chi phí - lợi ích mở rộng được sử dụng để đánh giá hiệu quả các dự án bằng cách tính thêm các chi phí, lợi ích môi trường đã bị bỏ qua trong phân tích chi phí - lợi ích kinh tế thuần.

Các chỉ tiêu tính toán $[8,9]$ :

i) Tỷ lệ chiết khấu: tất cả các chi phí và lợi ích trong tương lai được quy về giá trị hiện tại, do vậy việc xác định trục thời gian và tỷ lệ chiết khấu có tính chất đặc biệt quan trọng. Tỷ lệ chiết khấu đặc trưng cho khả năng giảm giá trị đồng tiền thu được hoặc đầu tư những năm tiếp theo so với năm hiện tại được chọn. Thường ước tính ban đầu của tỷ lệ chiết khấu có thể theo lãi suất mà các ngân hàng cho vay với loại dự án đang được xem xét.

ii) Giá trị hiện tại ròng: là giá trị lợi ích ròng hiện tại khi chiết khấu các dòng chi phí và lợi ích trở về năm bắt đầu thực hiện dự án (năm 0 ), được xác định theo công thức:

$$
N P V=\sum_{t=1}^{n} \frac{B_{t}}{(1+r)^{t}}-\left(C_{0}+\sum_{t=1}^{n} \frac{C_{t}}{(1+r)^{t}}\right)
$$

Trong đó: $\mathrm{C}_{0}$ : chi phí đầu tư ban đầu; $\mathrm{B}_{\mathrm{t}}$ : lợi ích năm thứ $\mathrm{t}$ (tính từ thời điểm hiện tại); $\mathrm{C}_{\mathrm{t}}$ : chi 
phí năm thứ t; r: tỷ lệ chiết khấu; n: tuổi thọ của dự án.

iii) Chỉ số hoàn vốn nội bộ IRR: là tỷ lệ chiết khấu làm cho giá trị hiện tại của lợi ích và chi phí bằng nhau. IRR được tính từ biểu thức NPV $=0$. Nếu IRR > $r$ thì dự án có hiệu quả và đáng được thực hiện, vì điều này thể hiện rằng đến hết tuổi thọ, dự án sẽ hoàn trả được vốn đầu tư và có lợi nhuận; Nếu IRR < r thì dự án không đem lại hiệu quả.

iv) Tỷ số lợi ích - chi phí: là tỷ lệ của tổng giá trị hiện tại của lợi ích so với tổng giá trị hiện tại của chi phí. Nếu tỷ số $\mathrm{B} / \mathrm{C}>1$ chứng tỏ dự án đem lại hiệu quả.

$$
\frac{B}{C}=\frac{\sum_{t=1}^{n} \frac{B_{t}}{(1+r)^{t}}}{C_{0}+\sum_{t=1}^{n} \frac{C_{t}}{(1+r)^{t}}}
$$

\subsection{Phuoong án tính toán và dũ liệu đầu vào}

Đối với tổ hợp Tân Rai, năm 2012 được chọn làm gốc thời gian năm 0 . Năm 2013, nhà máy alumina Tân Rai bắt đầu hoạt động, công suất hoạt động các năm 2013, 2014, 2015, 2016, 2017 lần lượt là $30 \%, 50 \%, 70 \%, 80 \%, 90 \%$. Từ năm 2018 , nhà máy hoạt động $100 \%$ công suất thiết kế. Thời gian hoạt động là 30 năm (từ 20132042). Trường hợp tổ hợp Nhân Cơ, năm 2016 được chọn làm gốc thời gian năm 0 . Nhà máy alumina Nhân Cơ bắt đầu hoạt động $77 \%$ công suất thiết kế vào năm 2017. Từ năm 2018, nhà máy hoạt động $100 \%$ công suất thiết kế. Thời gian hoạt động là 30 năm (2017-2046).

Chi phí vận hành tăng 1,5\%/năm. Giá alumina bình quân giai đoạn 2019-2042 là 411USD/tấn và giai đoạn 2019-2046 là 420 USD/tấn. Giả định sản phẩm alumina được sản xuất ra năm nào tiêu thụ hết năm đó, không có hàng tồn kho và các chi phí hàng năm được sử dụng hết.

Hai phương án được sử dụng để làm rõ sự khác nhau về hiệu quả tài chính và hiệu quả kinh tế môi trường, tương đương phương án 1 , phương án 2 đối với tổ hợp Tân Rai và phương án 3, phương án 4 đối với tổ hợp Nhân Cơ. Tỷ lệ chiết khấu được lựa chọn trong bài tính là $10 \%$, đây là lãi suất vay vốn mà doanh nghiệp đang chịu đối với vốn vay trong nước. Con số này cũng đồng thời phản ánh đầy đủ ý nghĩa của tỷ lệ chiết khấu, có tính đến khả năng sinh lời, các yếu tố lạm phát và rủi ro trong đầu tư [10].

Chi phí ngoại ứng đã được nội hoá và đưa vào tính toán gồm chi phí cơ hội, chi phí môi trường, chi phí trách nhiệm xã hội doanh nghiệp và chi phí dự phòng cho sự cố môi trường. Các khoản chi phí này được tính cho phương án 2 và phương án 4 (Bảng 2).

Chi phí cơ hội là một khái niệm rộng được xét toàn diện và có tính chọn lựa trong quyết định sản xuất trên cơ sở nguồn lực khan hiếm. Có thể hiểu chi phí cơ hội của một phương án được lựa chọn là giá trị của phương án tốt nhất bị bỏ qua khi thực hiện lựa chọn đó. Chi phí cơ hội của hoạt động khai thác, chế biến quặng bauxite là giá trị địa tô trên diện tích đất mà dự án sử dụng. Giá trị này bằng lợi nhuận từ việc trồng cây công nghiệp trừ đi tiền thuê đất hàng năm của doanh nghiệp, tương đương 65.446 triệu đồng/năm đối với tổ hợp Tân Rai và 75.965 triệu đồng/năm đối với tổ hợp Nhân Cơ.

Chi phí môi trường gồm chi phí giám sát môi trường và chi phí hoàn thổ, phục hồi môi trường sau khai thác: i) Chi phí giám sát môi trường hàng năm gồm có chi phí giám sát chất thải, chi phí giám sát môi trường xung quanh và chi phí lập báo cáo quan trắc môi trường theo chương trình giám sát cam kết trong báo cáo ĐTM của doanh nghiệp [11,12]. Áp dụng mức giá theo quy định với hoạt động quan trắc môi trường trên địa bàn các tỉnh Lâm Đồng và Đắk Nông, xác định được chi phí giám sát môi trường trong giai đoạn xây dựng dự án là 242.081.150 đồng/năm (được tính cho 5 năm từ 2008-2012 đối với tổ hợp Tân Rai và 7 năm từ 2010-2016 đối với tổ hợp Nhân Cơ), và trong giai đoạn hoạt động là 271.699.444 đồng/năm (tính từ năm 2013 đối với tổ hợp Tân Rai và từ năm 2017 đối với tổ hợp Nhân Cơ);

ii) Chi phí hoàn thổ, phục hồi môi trường sau khai thác: áp dụng đơn giá khoán trồng keo trong 5 năm trên địa bàn tỉnh Lâm Đồng là 
84.711.000đ/ha [13]. Tổng tiền phải trồng cây phục hồi môi trường khu vực tổ hợp Tân Rai là 186.364 triệu đồng/30 năm, trung bình 6.212 triệu đồng/năm, tương tự với khu vực tổ hợp Nhân Cơ là 347.315 triệu đồng/30 năm, trung bình 11.577 triệu đồng/năm.

Chi phí trách nhiệm xã hội của doanh nghiệp là các khoản chi phí thể hiện trách nhiệm của doanh nghiệp đối với cộng đồng và xã hội khu vực tổ hợp. Chi phí này là các khoản chi cho đền bù khi cộng đồng phải chịu thiệt hại do hoạt động của tổ hợp gây nên, các nghiên cứu hoặc đầu tư nâng cao chất lượng và cải thiện môi trường sống cho người dân khu vực chịu tác động của tổ hợp.
Trên cơ sở thực tế các sự cố đã xảy ra tại khu vực tổ hợp Tân Rai và Nhân Cơ, chi phí này được ước tính bằng $20 \%$ chi phí dự phòng sản xuất, tương đương trung bình 35.724 triệu đồng/năm đối với tổ hợp Tân Rai và 37.024 triệu đồng/năm đối với tổ hợp Nhân Cơ.

Chi phí dự phòng cho sự cố môi trường: gồm các khoản chi phí được sử dụng để dự phòng, khắc phục các rủi ro và sự cố môi trường xảy ra trong quá trình sản xuất, được ước tính bằng $5 \%$ các chi phí ngoại ứng khác, tương đương trung bình 24.946 triệu đồng/năm đối với tổ hợp Tân Rai và 28.318 triệu đồng/năm đối với tồ hợp Nhân Cơ.

Bảng 2. Dữ liệu đầu vào của các phương án tính toán (Đơn vị: triệu đồng/năm)

\begin{tabular}{|r|l|r|r|r|r|}
\hline TT & \multicolumn{1}{|c|}{ Nội dung } & \multicolumn{1}{c|}{ PA1 } & PA2 & PA 3 & PA4 \\
\hline I & \multicolumn{5}{|c|}{ Dòng lợ ích (B) } \\
\hline & - Doanh thu bán alumina & 5.884 .278 & 5.884 .278 & 6.275 .341 & 6.275 .341 \\
\hline II & \multicolumn{5}{|c|}{ Dòng chi phí (C) } \\
\hline 1 & - Chi phí đầu tư ban đầu [3] & 15.414 .436 & 15.414 .436 & 16.018 .058 & 16.018 .058 \\
\hline 2 & - Chi phí vận hành [3] & 3.915 .456 & 3.915 .456 & 4.054 .762 & 4.054 .762 \\
\hline 3 & - Chi phí ngoại ứng & 0 & 747.500 & 0 & 674.063 \\
\hline
\end{tabular}

\section{Kết quả nghiên cứu và thảo luận}

\subsection{Kết quả nghiên cưu}

Bảng 3. Kết quả phân tích chi phí - lợi ích tổ hợp bauxite - alumina Tân Rai và Nhân Cơ

\begin{tabular}{|c|l|r|r|r|r|}
\hline \multirow{2}{*}{ TT Chỉ tiêu tính toán } & \multirow{2}{*}{ Tổ hợp Tân Rai } & \multicolumn{2}{c|}{ Tổ hợp Nhân Co } \\
\cline { 3 - 6 } & & PA 1 & PA 2 & PA 3 & \multicolumn{1}{c|}{ PA 4 } \\
\hline 1 & r (\%) & 10 & 10 & 10 & 10 \\
\hline 2 & NPV (triệu đồng) & -2.600 .331 & -5.167 .422 & 4.037 .455 & 145.862 \\
\hline 3 & IRR (\%) & 8,4 & 6,27 & 12,9 & 10,1 \\
\hline 4 & B/C & 0,94 & 0,89 & 1,08 & 1,003 \\
\hline 5 & Thời gian thu hồi vốn (năm) & - & - & 15,1 & 27,1 \\
\hline 6 & Giá thành sản xuất bình quân (đồng/tấn) & 6.023 .778 & 6.784 .455 & 6.238 .097 & 7.275 .115 \\
\hline 7 & Giá bán bình quân (đồng/tấn) & 9.052 .735 & 9.052 .735 & 9.654 .371 & 9.654 .371 \\
\hline 8 & Chi phí môi trường (đồng/tấn) & 0 & 760.677 & 0 & 918.670 \\
\hline 9 & Lợi nhuận trước thuế (triệu đồng/năm) & 1.968 .822 & 1.211 .322 & 2.220 .579 & 1.546 .516 \\
\hline 10 & Lợi nhuận sau thuế (triệu đồng/năm) & 1.310 .088 & 551.589 & 1.452 .360 & 892.755 \\
\hline 11 & Các khoản thuế, phí (triệu đồng/năm) & 760.055 & 659.733 & 778.219 & 663.762 \\
\hline $11 . \mathrm{a}$ & • Thuế thu nhập doanh nghiệp & 276.363 & 176.041 & 284.881 & 170.424 \\
\hline
\end{tabular}




\begin{tabular}{|c|l|r|r|r|r|}
\hline $11 . \mathrm{b}$ & $\bullet$ Thuế xuất khẩu & 137.198 & 137.198 & 124.700 & 124.700 \\
\hline $11 . \mathrm{c}$ & $\bullet$ Phí MT & 129.540 & 129.540 & 135.000 & 135.000 \\
\hline $11 . \mathrm{d}$ & $\bullet$ Thuế TN & 202.082 & 202.082 & 210.600 & 210.600 \\
\hline $11 . \mathrm{e}$ & $\bullet$ Tiền cấp quyền khai thác khoáng sản & 14.872 & 14.872 & 23.038 & 23.038 \\
\hline $11 . \mathrm{f}$ & $\bullet$ Tiền thuê đất & 9.724 & 9.724 & 6.396 & 6.396 \\
\hline \multirow{2}{*}{$11 . \mathrm{g}$} & Bình quân thuế, phí/1 tấn alumina & \multicolumn{2}{|c|}{$\begin{array}{c}1.003 .730 \\
\text { VNĐ/tấn alumina }\end{array}$} & \multicolumn{2}{|c|}{$\begin{array}{c}1.031 .012-1.207 .100 \\
\text { VNĐ/tấn alumina }\end{array}$} \\
\hline
\end{tabular}

Kết quả phân tích tài chính tổ hợp Tân Rai khi không thực hiện việc nội hóa các chi phí ngoại ứng cho giá trị NPV là -2.600 .331 triệu đồng, $\mathrm{IRR}=8,4 \%<\mathrm{r}(10 \%), \mathrm{B} / \mathrm{C}$ bằng 0,94 . Kết quả phân tích chi phí - lợi ích mở rộng khi nội hóa các chi phí ngoại ứng vào chi phí vận hành hàng năm của doanh nghiệp cho giá trị NPV là (-5.167.422) triệu đồng, IRR $=6,27 \%<\mathrm{r}(10 \%)$, $\mathrm{B} / \mathrm{C}$ bằng 0,89 . Từ kêt quả này cho thấy, hoạt động của tổ hợp Tân Rai không đem lại hiệu quả trên quan điểm kinh tế môi trường.

Đối với tổ hợp Nhân Cơ, kết quả phân tích tài chính (PA3) cho giá trị NPV là 4.037.455 triệu đồng, $\mathrm{IRR}=12,9 \%>\mathrm{r}(10 \%), \mathrm{B} / \mathrm{C}$ bằng 1,08 , thời gian thu hồi vốn là 7 năm 9 tháng. Kết quả phân tích chi phí - lợi ích mở rộng (PA4) cho thấy nếu nội hóa các chi phí ngoại ứng thì giá trị NPV là 145.862 triệu đồng, $I R R=10,1 \%>r$ $(10 \%), \mathrm{B} / \mathrm{C}$ bằng 1,003 , thời gian thu hồi vốn là 8 năm 10 tháng. Điều này cho thấy tổ hợp Nhân Cơ đạt hiệu quả kinh tế môi trường và doanh nghiệp có khả năng trả nợ khoản vay lãi suất $10 \%$. Thời gian thu hồi vốn của phương án 3 là 15 năm 1 tháng, phương án 4 là 27 năm 1 tháng, cho thấy nếu nội hóa các chi phí ngoại ứng thì thời gian hoàn vốn sẽ chậm hơn 12 năm so với việc không đưa chi phí này vào bài tính. Kết quả phân tích ở Bảng 3 cho thấy tổ hợp Nhân Cơ hoạt động hiệu quả hơn và có các chỉ tiêu tài chính cao hơn so với tổ hợp Tân Rai, điều này trái ngược với những công bố về hiệu quả tài chính của doanh nghiệp cách đây 7 năm tại Bảng 1 .

Giá thành sản xuất bình quân ở $\mathrm{PA} 1$ và $\mathrm{PA} 2$ chênh nhau 11\%: 6.023 .778 triệu đồng/tấn đối với PA1 và 6.784 .455 triệu đồng/tấn đối với $\mathrm{PA} 2$. Giá thành sản xuất bình quân ở $\mathrm{PA} 3$ và PA4 chênh nhau 14\%: 6.238 .097 triệu đồng/tấn đối với PA3 và 7.275.115 triệu đồng/tấn đối với
PA 4. Do giá thành sản xuất bình quân khác nhau nên dẫn đến sự chệnh lệch trong lợi nhuận bình quân trước thuế của các phương án cũng có sự khác biệt: phương án 1 (1.968.822 triệu đồng) và phương án 2 (1.474.382 triệu đồng) chênh nhau $34 \%$, phương án 3 (2.220.579 triệu đồng) và phương án 4 (1.546.516 triệu đồng) chênh nhau $44 \%$. Nếu tính thêm các chi phí môi trường, giá thành sản xuất tăng thêm 760.677 đồng, tương đương 32,7USD/tấn sản phẩm alumina đối với tổ hợp Tân Rai và tăng thêm bình quân 918.670 đồng, tương đương 39,5USD/tấn sản phẩm đối với tổ hợp Nhân Cơ. Có thể thấy, để tối đa hoá lợi nhuận, doanh nghiệp thường có xu hướng cắt giảm các khoản chi phí, đặc biệt là những chi phí liên quan đến môi trường.

Thuế thu nhập doanh nghiệp phải đóng ở các phương án 1 và 2 lần lượt là $276.363,176.041$ triệu đồng/năm, chênh nhau 100,3 tỷ đồng/năm; ở các phương án 3 và 4 lần lượt là 284.881 , 170.424 triệu đồng/năm, chênh nhau 114,5 tỷ đồng/năm. Nếu doanh nghiệp hạch toán đầy đủ các khoản chi phí môi trường vào giá thành sản phẩm, chi phí sản xuất hàng năm sẽ tăng, dẫn đến giá trị NPV của tổ hợp giảm. Điều này đồng nghĩa với việc lợi nhuận ròng của tổ hợp giảm, thuế thu nhập doanh nghiệp phải đóng cũng giảm theo. Như vậy, việc tuân thủ các quy định về bảo vệ môi trường đem lại lợi ích cho xã hội, đồng thời doanh nghiệp cũng được hưởng lợi ích thông qua việc giảm các khoản thuế, phí đóng góp cho Nhà nước. Trong trường hợp này, doanh nghiệp sẽ tiết kiệm được 100,3-114,5 tỷ đồng thuế thu nhập doanh nghiệp phải đóng hàng năm cho một tổ hợp, tương đương hơn 200 tỷ đồng cho hai tổ hợp Tân Rai và Nhân Cơ. Đây là chính sách ưu đãi của Nhà nước để khuyến khích doanh nghiệp thực hiện các nội dung về bảo vệ 
môi trường trong hoạt động sản xuất. Do vậy, doanh nghiệp nên thực hiện đầy đủ các quy định về bảo vệ môi trường và hạch toán những chi phí này vào giá thành sản phẩm để được hưởng khoản chênh lệch khi đóng thuế.

Các tổ hợp Tân Rai và Nhân Cơ đều mất 6-7 năm để hoàn thành giai đoạn đầu tư ban đầu, việc kéo dài dẫn đến tăng gấp 2 lần tổng vốn đầu tư. Trong tương lai, nếu các dự án bauxite - alumina được triển khai đúng tiến độ thì hiệu quả của chúng sẽ được cải thiện rõ rệt. Kết quả phân tích chi phí - lợi ích tổ hợp Nhân Cơ cho thấy, mỗi tấn alumina sản xuất ra cần 918.670 đồng chi phí môi trường và đóng góp 1.207.100 đồng các khoản thuế, phí vào ngân sách nhà nước. Ngoài ra, tổ hợp còn tạo việc làm ổn định cho hơn 1.100 lao động và góp phần thúc đẩy phát triển kinh tế - xã hội khu vực diễn ra hoạt động khai thác, chế biến khoáng sản bauxite, đem lại lợi ích chung cho xã hội Tây Nguyên.

\subsection{Phân tích độ nhạy}

Tổ hợp Tân Rai và Nhân Cơ với cùng quy mô công suất, cùng công nghệ sản xuất và chi phí đầu tư ban đầu gần tương đương, nhưng kết quả phân tích chi phí - lợi ích của hai tổ hợp lại cho thấy hiệu quả của chúng khác nhau. Sở dĩ có sự khác biệt này là do ba nguyên nhân. Một là, sau khi hoàn thiện quá trình đầu tư cơ bản, tổ hợp Tân Rai mất 6 năm mới vận hành được $100 \%$ công suất thiết kế, trong khi tổ hợp Nhân Cơ vận hành $100 \%$ công suất thiết kế từ năm thứ 2 . Hai là, tổ hợp Tân Rai đi vào vận hành từ năm 2013, đúng thời điểm giá alumina trên thị trường đang ở mức thấp. Trong khi tổ hợp Nhân Cơ bắt đầu sản xuất từ năm 2017, vào thời điểm giá alumina trên thị trường phục hồi và đạt mức tăng kỉ lục vào năm 2018. Ba là, doanh nghiệp đã cắt giảm chi phí đầu tư xây dựng hồ bùn đỏ ở tổ hợp Nhân Cơ giảm đi một nửa so với chi phí này của tổ hợp Tân Rai. Những nguyên nhân trên đã làm ảnh hưởng đáng kể đến kết quả phân tích chi phí - lợi ích. Mặt khác, kết quả tính toán cũng có thể thay đổi phụ thuộc vào độ nhạy của các thông số. Do vậy, sau khi tính toán kết quả phân tích chi phí lợi ích mở rộng, các số liệu đầu vào được thay đổi để xem xét biến động của chỉ số NPV. i) Biến động tỷ lệ chiết khấu (r): tỷ lệ chiết khấu có vai trò quan trọng trong việc quy đổi dòng tiền về cùng một thời điểm nhất định. Tỷ lệ này không cố định mà có thể khác nhau tuỳ mục đích sử dụng của từng cá nhân, doanh nghiệp, dự án, phương án sử dụng tài nguyên hoặc dựa trên quan điểm của doanh nghiệp hay xã hội. Tuy nhiên, tỷ lệ chiết khấu được sử dụng để tính toán chi phí - lợi ích mở rộng phải đảm bảo được đầy đủ các yếu tố: chi phí cơ hội của vốn, có tính đến yếu tố rủi ro và lạm phát. Kết quả phân tích độ nhạy cho thấy, với mức thay đổi dao động trên dưới $20 \%$ của tỷ lệ chiết khấu $\mathrm{r}$ (từ $8 \%$ đến $12 \%$ ), nếu tính đầy đủ các chi phí môi trường thì NPV của tổ hợp Tân Rai vẫn mang dấu âm, còn NPV của tổ hợp Nhân Cơ sẽ âm nếu $\mathrm{r}$ lớn hơn hoặc bằng $10,2 \%$. Điều này có nghĩa rằng nếu tỷ lệ $\mathrm{r}$ càng lớn thì hoạt động của các tổ hợp tiềm ẩn nhiều rủi ro.

ii) Giá trị hiện tại ròng NPV của tổ hợp Tân Rai (PA2) sẽ mang giá trị dương nếu như giá alumina thị trường giai đoạn 2020-2042 ở mức cao hơn 470USD/tấn hoặc chi phí vận hành của tổ hợp giảm $50 \%$. Những điều này là rất khó xảy ra bởi các yếu tố này đều phụ thuộc chủ yếu vào thị trường, trong khi giá alumina hiện nay đang ở mức thấp.

iii) Tổ hợp Nhân Cơ sẽ không đạt hiệu quả nếu giá alumina thị trường 2020-2046 ở mức thấp hơn 395USD/tấn hoặc biến động chi phí vận hành tăng lớn hơn $1,5 \% /$ năm. Những điều này được cho là có khả năng xảy ra trong bối cảnh giá alumina thị trường năm 2019 giảm mạnh xuống còn 294USD/tấn. Theo dự báo của các tổ chức uy tín trên thế giới, giá alumina trên thị trường sẽ tăng nhẹ trong những năm tới, nhưng dự báo biến động không nhiều do nguồn cung alumina thế giới năm 2019 đã ở mức dư thừa. Nguyên nhân là do nhà máy alumina công suất 6,3 triệu tấn tại Brazil đã hoạt động trở lại sau khi hết lệnh cấm và nhiều nhà sản xuất nhôm trên thế giới đã đầu tư xây dựng nhà máy alumina để làm chủ nguồn nguyên liệu đầu vào sau sự cố giá alumina tăng đột biến ở mức trung bình 472USD/tấn, có thời điểm lên đến 707USD/tấn vào năm 2018. 
iv) Ở phương án phân tích tài chính tổ hợp Nhân Cơ (PA3), chi phí xây dựng hồ bùn đỏ được tính theo thực tế triển khai và bằng một nửa so với tổ hợp Tân Rai (PA1 và PA2). Việc cắt giảm chi phí này đã cải thiện hiệu quả hoạt động sản xuất kinh doanh của doanh nghiệp, tuy nhiên lại làm phát sinh vấn đề môi trường khi khoang chứa bùn đỏ số 2 (khoang dự phòng) của tổ hợp Nhân Cơ đã xảy ra sự cố liên quan đến sụt lún ở trong lòng hồ và khu vực lân cận nhiều lần vào mùa mưa các năm 2017, 2018, 2019.

Phương án phân tích chi phí - lợi ích mở rộng (PA4) sử dụng dữ liệu đầu vào là chi phí xây dựng hồ bùn đỏ của tổ hợp Nhân Cơ bằng chi phí này ở tổ hợp Tân Rai, kết quả tính toán cho thấy hoạt động sản xuất vẫn đem lại hiệu quả kinh tế, dù giá trị không cao và tiềm ẩn rủi ro về tài chính, nhưng đảm bảo được đầy đủ các nội dung liên quan đến bảo vệ môi trường trong hoạt động khai thác khoáng sản như hoàn thổ phục hồi môi trường, quan trắc giám sát môi trường, chi đầy đủ chi phí xây dựng hồ bùn đỏ, có tính đến chi phí cơ hội và chi phí trách nhiệm xã hội của doanh nghiệp.

\section{Kết luận}

Phương pháp phân tích chi phí - lợi ích thường được sử dụng theo hai hướng là phân tích tài chính và phân tích chi phí - lợi ích mở rộng. Phương pháp phân tích tài chính nghiên cứu khả năng sinh lời theo hướng tối thiểu hoá chi phí sản xuất, do đó những khoản chi phí cho môi trường và xã hội về cơ bản bị bỏ qua. Khi sản lượng nhà máy alumina tăng lên, tổng lượng chất ô nhiễm phát thải sẽ tăng lên do quá trình tích lũy lâu dài. Tuy nhiên, chi phí sản xuất của mỗi tấn alumina chỉ phản ánh số tiền mà doanh nghiệp trả cho việc khai thác nguyên liệu (khai thác bauxite, tuyển rửa,...), hóa chất, vận chuyển, chi phí lao động,... mà không hề có khoản chi phí cho giảm thiểu, giám sát và xử lý ô nhiễm gây ra trong quá trình sản xuất. Do đó, kết quả tính toán không phản ánh đúng hiệu quả hoạt động của nền kinh tế. Dưới góc độ quản lý vĩ mô, hoạt động sản xuất là quá trình phát triển đảm bảo lợi ích đồng đều trong ba lĩnh vực kinh tế, xã hội, môi trường.
Chính vì vậy, cần thực hiện phân tích chi phí lợi ích mở rộng để đưa ra cái nhìn tổng thể và khách quan về hiệu quả của hoạt động khai thác, chế biến quặng bauxite tại các dự án thí điểm ở khu vực Tây Nguyên.

Kết quả phân tích chi phí - lợi ích mở rộng tổ hợp Tân Rai cho giá trị NPV là (-5.167.422) triệu đồng, $\mathrm{IRR}=6,27 \%<\mathrm{r}(10 \%), \mathrm{B} / \mathrm{C}$ bằng 0,89 , cho thấy nếu tính toán đầy đủ các khoản chi phí môi trường và xã hội thì tổ hợp không đem lại hiệu quả. Kết quả phân tích chi phí - lợi ích mở rộng của tổ hợp Nhân Cơ cho giá trị NPV là 145.862 triệu đồng, $\mathrm{IRR}=10,1 \%>\mathrm{r}(10 \%), \mathrm{B} / \mathrm{C}$ bằng 1,003 , thời gian thu hồi vốn là 27 năm 01 tháng, điều này cho thấy hoạt động của tổ hợp đem lại hiệu quả theo quan điểm kinh tế môi trường. Nếu thực hiện đúng các quy định về bảo vệ môi trường, trung bình 1 tấn sản phẩm alumina sản xuất ra cần $0,7-0,9$ triệu đồng chi phí môi trường.

Tổng chi phí đầu tư bổ sung để xây dựng hồ chứa bùn đỏ trong 30 năm của tổ hợp Tân Rai là rất lớn, khoảng trên 3.000 tỷ đồng. Tuy nhiên, để cải thiện hiệu quả của các tồ hợp bauxitealumina trong tương lai, không nên cắt giảm chi phí xây dựng hồ chứa bùn đỏ như thực tế đang làm với tổ hợp Nhân Cơ. Thực tế cho thấy chất lượng hồ chứa bùn đỏ tại Nhân Cơ không đảm bảo và tiềm ẩn nhiều rủi ro, đã xuất hiện hiện tượng sụt lún lòng hồ xảy ra hàng năm vào mùa mưa, cho thấy hiệu quả môi trường đã giảm tương ứng. Do vậy, cần có giải pháp về quy trình công nghệ hướng tới bùn đỏ thải ra ở dạng khô, dễ dàng lưu trữ và tái sử dụng hơn, góp phần giảm chi phí, hạn chế các tác động tiêu cực tới môi trường, qua đó giải quyết được mối lo lớn nhất về môi trường cho các dự án khai thác, chế biến quặng bauxite sau này [14]. Đồng thời, cần xây dựng các phương án cải thiện hiệu quả hoạt động khai thác, chế biến quặng bauxite Tây Nguyên trong tương lai và tính toán phân tích chi phí - lợi ích mở rộng trên cơ sở hướng tới hình thành chuỗi sản xuất khép kín ngành công nghiệp nhôm, từ khai thác quặng bauxite, sản xuất alumina, điện phân nhôm, tận dụng bùn thải quặng đuôi và tái sử dụng bùn đỏ, dần hình thành mô hình kinh tế tuần hoàn, khép kín trong sản xuất, ít tạo ra chất thải. 
Đã một thập kỷ trôi qua kể từ sau chỉ đạo của Bộ Chính trị về việc thực hiện các dự án bauxitealumina thí điểm ở khu vực Tây Nguyên, Việt Nam đã tham gia vào thị trường xuất khẩu alumina được 7 năm và dần làm chủ công nghệ chế biến quặng bauxite. Kết quả phân tích chi phí - lợi ích mở rộng hai dự án bauxite - alumina đã chỉ ra những điểm tích cực và cả những tồn tại cần khắc phục, làm cơ sở để điều chỉnh, xây dựng và triển khai các dự án khai thác, sử dụng tài nguyên bauxite hợp lý hơn trên vùng đất Tây Nguyên. Doanh nghiệp khai thác, chế biến khoáng sản bauxite nên thực hiện đầy đủ các biện pháp bảo vệ môi trường theo quy định của pháp luật và hạch toán vào chi phí sản xuất để được giảm trừ khi đóng thuế thu nhập. Trong tương lai, các dự án khai thác, chế biến bauxite tại khu vực Tây Nguyên cần được triển khai đúng tiến độ và vận hành $100 \%$ công suất thiết kế từ năm đầu tiên để đạt mức hiệu quả tối ưu.

\section{Tài liệu tham khảo}

[1] World Aluminium, Sustainable Bauxite Mining Guidelines. http://www.world-aluminium.org/med ia/ filer_public/2018/05/18/170518_sbmg_final.pdf, 2018 (accessed 15 April 2020).

[2] U.S. Geological Survey, Mineral commodity summaries 2019: U.S. Geological Survey, U.S., 2019, 200p. https://doi.org/10.3133/70202434.

[3] VUSTA, Proceedings of Bauxite in the Central Highlands Conference: States, Orientation and Recommendations, Hanoi, May 2013 (in Vietnamese).

[4] Dang Trung Thuan, Trinh Phuong Ngoc, Exploiting and processing of bauxite in Tan Rai complex in the Central Highlands- 5 years searching for a path. Proceedings of the 2nd Science and Technology Conference: Natural Resources, Energy and Environment for Sustainable Development, Ho Chi Minh City University of Natural Resources and Environment, Ho Chi Minh, 2014, pp. 807819 (in Vietnamese).

[5] Vietnam Government, Decree on Export tariff schedule, preferential import tariff, list of goods and absolute tax, compound tax, import tax out of tariff quota, No.122/2016/ND-CP, Hanoi, September 2016. https://bientap.vbpl.vn//FileData /TW/Lists/vbpq/Attachments/113263/VanBanGo c 122.2016.ND.CP.pdf (in Vietnamese).

[6] Vietnam Ministry of Finance, Circular stipulating the price bracket for calculation of resource tax for groups and types of resources with similar physical and chemical properties, No.44/2017/TTBTC, Hanoi, 2017. http://datafile.chinhphu.vn/ file-remote-v2/DownloadServlet?filePath=vbpq/ 2017/07/44-BTC.signed.pdf (in Vietnamese).

[7] NSW Goverment, Guide to Cost-Benefit Analysis (TPP17-03). https://www.treasury.nsw.gov.au/sit es/default/files/2017-03/TPP17-03\%20NSW\%20 Government $\% 20$ Guide $\% 20$ to $\% 20$ Cost-Benefit $\%$ 20Analysis\%20-\%20pdf_0.pdf, 2017, (accessed 15 April 2020).

[8] Nguyen Thuy Duong, Tran Tuan Anh, Mineral resource management by assessing economic, social and environmental effects. Vietnam Journal of Earth Sciences 36 (3) (2014) 204-213. http://sti. vista.gov.vn/file_DuLieu/dataTLKHCN//CVv117 /2014/CVv117V36S32014204.pdf (in Vietnamese).

[9] Duong Thi Thanh Xuyen, Tran Nghi, Do Thi Ngoc Thuy, Nguyen Dinh Thai, Do Manh Thuan, Cost benefit analysis of the exploitation of several important natural resources in the Coastal Zone in Binh Thuan Province, VNU Journal of Science: Earth and Environmental Sciences 33(3) (2017) 79-86. https://doi.org/10.25073/2588-1094/vnuee s.4124 (in Vietnamese).

[10] Nguyen Quang Ha, Identification discount rate in asset pricing and project analysis, Vietnam Journal of Forestry Science and Technology 01 (2014) 103-108. http://sti.vista.gov.vn/file DuLieu/dataT LKHCN//CVv421/2014/CVv421S012014103.pdf (in Vietnamese).

[11] VINACOMIN, Environmental Impact Assessment Report of Lam Dong bauxite-alumina complex, Hanoi, 2009 (in Vietnamese).

[12] VINACOMIN, Environmental Impact Assessment Report of Nhan Co bauxite-alumina complex, Hanoi, 2010 (in Vietnamese).

[13] People's Committee of Lam Dong, Decision on unit price of replacement afforestation; afforestation after clearance; afforestation under the program of sustainable forest protection and development in Lam Dong province, No.994/QD -UBND, Lam Dong, May 2016. https://thuvienphapluat.vn/vanban/tai-chinh-nha-nuoc/Quyet-dinh-994-QD-UB ND-don-gia-trong-rung-thay-the-trong-rung-saugiai-toa-Lam-Dong-2016-311539.aspx Vietnamese).

[14] Luu Duc Hai, Technology for alumina production and environmental issues arising in alumina production technology in Vietnam, Vietnam Journal of Environmental Economics 153 (2019) 48-53. https://kinhtemoitruong.vn/bao-giay/tap-chi kinh-te-moi-truong-so-153-thang-82019.paper (in Vietnamese). 